\title{
Enhancement the octane number of sudanese gasoline (Nile Blend)
}

\author{
Sedahmed Osman ${ }^{1}$, Omar K. Duaij ${ }^{2}$, Kamal K. Taha ${ }^{2 *}$ \\ ${ }^{1}$ Department of Chemistry-Elneelain University-Khartoum, Sudan \\ ${ }^{2}$ Dept. of Chem., College of Science, Al Imam Mohammad Ibn Saud Islamic University (AMSIU), P.O. \\ Box : 5701, Riyadh, KSA \\ *E-mail address: kamaltha99@rediffmail.com
}

\begin{abstract}
Gasoline is one of most important sources of energy but when manufactured with low octane number may leave great risk that affect the human health and environment impact. Therefore processes of gasoline production must be developed. Zeolite material dependence on their extremely high frame work extended interactive surface, ability to interact with molecule and cations. They show a wide variety of interesting properties which result in remarkable applications in the fields of catalysts, gas separations, selective adsorption and water softening. Zeolite catalyst loaded with finely ( $\mathrm{Sr}$ ) metal have been used in hydro-cracking, catalytic cracking. The zeolite used is the synthetic zeolite (type Y) has high thermal stability, good surface area and its heterogeneous catalyst which can be separated after treatment and may be reactivated. The study of the octane number was carried out for this zeolite. The gasoline was obtained from market (commercial gasoline) it has octane number 91.7 determined by IROX-2000.The gasoline was treated by zeolite in the temperature about 331 Kelvin. The synthetic zeolite (type-Y) raised the octane number (from 91.7 to 92.4 ).
\end{abstract}

Keywords: octane number; sudanese gasoline; Nile Blend

\section{INTRODUCTION}

Sudan has two sorts of crude. They are different in quality and price. Sudan's Nile Blend crude is sold at much higher prices than Dar Blend crude(1). Nile blend is the one of the best crude qualities, it contains a little amount of impurities and high chemical properties, which require low invested and operational costs to produce best quality products. It is of the medium density, which reach 34 API degree, its pour point range between $33-36{ }^{\circ} \mathrm{C}$ centigrade, and sulphur composition content is low, not exceeding $4 \%$ weight. However its complicated aromatic complex content can be ignored from the practical aspect (2). As crude oil comes from its well containing a mixture of hydrocarbon compounds and relatively small quantities of other materials such as oxygen, nitrogen, sulphur salt and water. In the refinery most of these non-hydrocarbon substances are removed and the oil is broken down into its various components, and blended into useful products (3). These component can be separated easily as they have different boiling temperatures, by fractional distillation (4). At about $40-70^{\circ} \mathrm{C}$ gasoline, which it is largely 
a mixture of hydrocarbons, can be separated. Some may also contain significant quantities of ethanol and $\backslash$ or s mall quantities of additives such as tert-arybutylmethyl ether as anti-knock agents to increase the octane rating. The hydrocarbons consist of a mixture of n-paraffins, naphthenes, olefins and aromatics. Naphthenes, olefins and aromatics increase the octane rating of the gasoline whereas the n-paraffins have the opposite effect. The aromatics are mostly a mixture of benzene, toluene and the xylenes. The benzene content is kept to a minimum (but is not negligible) due to its perceived toxicity. Originally lead tetraethyl was added as an anti-knock agent but is now rarely used and is prohibited in most countries due to its toxicity(5)

By definition an octane number is that percentage of isooctane in a blend of isooctane and normal heptane that exactly match the knock behavior of the gasoline. Thus of octane gasoline matches the knock characteristic of blend containing 90\% isooctane and $10 \% \mathrm{n}$ heptane. The octane numbers, as defined by ASTM methods, is an empirical property. It cannot be submitted to any analysis that would allow octane optimizing strategies. There fore it must be related to measurable properties inherent to gasoline, such as its molecular composition. The relation between the structure of hydrocarbons and their octane number was studied using a number of topological indices. A physicochemical discussion about the meaning of octane number on the molecular level, however, did not go beyond some empirical rules:

- ON increases with the number of tertiary and quaternary carbon atoms $[2,6]$ respectively it increases with the number of methyl groups. [13-15]

- It decreases with the total number of carbon atoms $[2,6]$ respectively with the length of the chain [13-15]

- ON gets larger as the branching point is moving toward the center of the longest chain in the alkane molecule [6].

Zeolites are micro-porous crystalline solids with well-defined structures. Generally they contain silicon, aluminium and oxygen in their framework and cations, water and/or other molecules within their pores [7]. The natural zeolite faujasite has the same framework (FAU) and similar framework composition to the Type Y synthetic zeolite but is rare in nature [8]. From the early 1960s, use of synthetic zeolites in catalysis and in related adsorption separation processes has dramatically transformed petroleum refining by vastly increasing the yield of high-quality fuels and reducing capital and operating costs, energy requirements, and adverse environmental impact [9] In modern petroleum refineries in the world, gasoil and other heavier fractions from the crude oil fractionation unit are fed to fluid catalytic cracking units, which use small, fluidizable catalyst particles containing Type Y zeolite or other zeolites, or to hydro cracking units, which use fixed beds of larger catalyst particles also containing zeolites [10 -12].

Many zeolites can be synthesized with $\mathrm{SiO}_{2}$ higher or lower than in nature for the same framework type. Higher $\mathrm{SiO}_{2}$ generally gives greater hydrothermal stability, stronger-acid catalytic activity, and greater hydrophobicity as adsorbents. Conversely, lower $\mathrm{SiO}_{2}$ gives greater cation exchange capacity and higher adsorbance for polar molecules. Controlling the synthesis process optimizes a zeolite for different applications [13].

The fluid catalytic cracking and hydrocracking units convert higher-molecularweight hydrocarbons to lighter ones suitable for gasoline, light fuel oils, olefins, and other uses [14]. Zeolite $\mathrm{Y}$ with $\mathrm{Si} / \mathrm{Al}=2.5-3$ stability is increased by ion exchange with rare earth cations [15] ZSM - 5 with pore size $\approx 1.2 \mathrm{~nm}$ was reported to have a high reaction selectivity for n-alkanes cracking over acidic centers by forming a secondary or tertiary carbonium ions from a beta $\mathrm{C}-\mathrm{C}$ bond. This process leads to production of propenes or 
butenes from long chain n-alkanes [15].

Unfortunately, tetraethyl lead and other metal and non-metal additives for octane boosting or octane improvement of gasoline such as other lead compounds, manganese compounds, boron compounds, phosphorous compounds, etc., deactivate or poison the catalyst in the catalytic converters so that the converter cannot reduce the noxious emissions to acceptable levels [16]. Therefore the use of zeolites as safe natural material was done in this study. Zeolites were prepared from clays and materials available in Sudan. The synthesized zeolite was employed in enhancement of octane number of fuel.

\section{MATERIALS AND METHODS}

\subsection{Materials}

The chemical below were obtained from natural sources as in table 1 . They were used as received without further purification:

Table 1. Raw material for the synthesis of zeolite.

\begin{tabular}{|c|c|c|}
\hline Name & Source & Purity \\
\hline Clay & River Nile & Natural \\
\hline Sodium carbonate & Alfasher & Natural \\
\hline Strontium nitrate & Loba India & Analytical Reagent \\
\hline K-Feldspar $\underline{\mathrm{KAlSi}}_{3} \underline{\mathrm{O}}_{8}$ & Bioda desert & Natural \\
\hline Sudanese gasoline & Refinaery & \\
\hline
\end{tabular}

\subsection{Instruments}

Thermal Gravimetric Analysis (TGA), FT-IR (SHIMADZU 84005), IROX-2000, Density meter (Anton par), Sensitive balance, water bath, Electric Furnace (1273 K - $1437 \mathrm{~K}$ Carbolite)

\subsection{Preparation of synthetic zeolite}

The procedure of preparation of synthetic zeolite consists of the following steps: powder,

a-The $\mathrm{K}$ feldspar was extracted from rocks with jaw and crusher, then crushed till

b- The clay was crushed with mortar and pestle.

c- The trona (sodium carbonate) was crushed till became powder.

d- The mixture of clay, K- feldspar, sodium carbonate and strontium nitrate were placed in the clean crucible of porcelain as in the following ratios clay: K-feldspar: sodium carbonate: strontium nitrate $(39.2: 39.2: 19.6: 1.96)$. hours.

e- The mixture was heated in the electric furnace at a temperature of $1373 \mathrm{~K}$ for six

f- After that the crucible was taken away from the furnace and cooled. Finally the synthetic zeolite was crushed and was ready to use. Synthesized zeolite was characterized by XRD, TGA (thermal gravimetric analysis) and FT-IR. 


\section{XRD, FT-IR and TGA analysis of zeolite}

X-ray diffraction (XRD) for zeolites A was analyzed following the standard method [17]. Experiment was performed using a Philips PW1732/10 diffractometer and CuKa radiation and Ni filter. The working conditions of this experiment were $40 \mathrm{kV}$ and $20 \mathrm{~mA}$. Also zeolites A was analyzed by Fourier Transform Infra Red(FT-IR), in which a mixture of $0.005 \mathrm{~g}$ of zeolite A and $0.2 \mathrm{~g}$ of $\mathrm{KBr}$ were pressed into disk for IR measurement [18]. Thermo gravimetric analyzer instrument manual, the STA PT1600 is a highly versatile research to controlled temperature environment (TG). Temperature range $323 \mathrm{~K}$ to $723 \mathrm{~K}$ and heating rate $(273.1$ to $373 \mathrm{~K} / \mathrm{min})$, max sample weight $25 \mathrm{~g}$, resolution $0.5 \mu \mathrm{g}$. in this research we can analyzed at $723 \mathrm{~K}$ and rate $10^{\circ} \mathrm{C}$ min.

\section{Treatment process of gasoline by zeolite}

In the clean bottle the 2.5 liters of gasoline was taken, and $119 \mathrm{~g}$ of zeolite were added to this gasoline the mixture was shaken gently and it was put in a water bath at $\approx$

$331 \mathrm{~K}$ till boiling of gasoline, and time was recorded. After that the mixture was cooled and the octane number, density, copper strip corrosion of gasoline was measured.

\section{Determination of the octane number}

For determination the research octane number (RON) the American Society for Testing and Materials (ASTM) method (ASTM D2699) was used. About 150 of gasoline was taken to measure the octane number of gasoline after and before treatment, by using IROX-2000 (is an extremely compact, robust and user friendly Mid-FTIR spectrometer for the automatic measurement of the concentration of the most important components of gasoline). This instrument was operated in the following conditions; display in the large graphics display, back lit. warm up time 10 min response time 3 minutes and the retention time of the treated sample is 7 days.

\section{Determination of density}

For determination of density the ASTM method (D-1298) was used. A small volume (Approximately $0.7 \mathrm{ml}$ ) of gasoline was introduced into an oscillating sample tube and the change in oscillating frequency caused by the change of the mass of tube which was used in conjunction with calibration data to determine the density of the sample.

\section{Copper strip corrosion}

A polished copper strip is immersed in a specific volume of the sample being tested and heated under conditions of temperature and time $\left(3 \mathrm{~h} / 50^{\circ} \mathrm{c}\right)$ that are specific to the class of material being tested. At the end of the heating period, the copper strip is removed, washed and the color and tarnish level assessed against the ASTM (D130) Copper Strip Corrosion standard. 


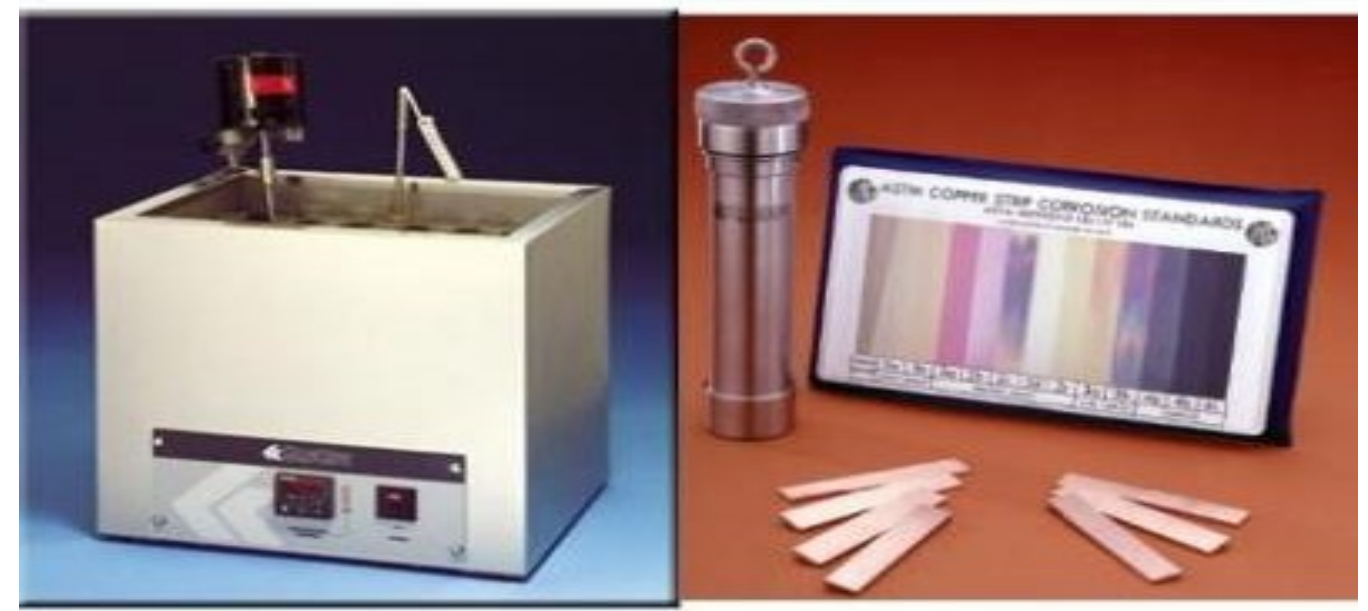

Fig. 1. Copper strip corrosion instrument.

\section{RESULTS AND DISCUSSION}

The XRD pattern of the synthesized is shown in figure (2). The characteristic peaks of Y zeolite at $2 \Theta=6.5^{\circ}(2), 10.1^{\circ}(3), 15.6^{\circ}(6)$ and $23.7^{\circ}(7)$ [19] indicate the its formation. The pattern is matching with that of commercial zeolite Y (Fig. 2b).

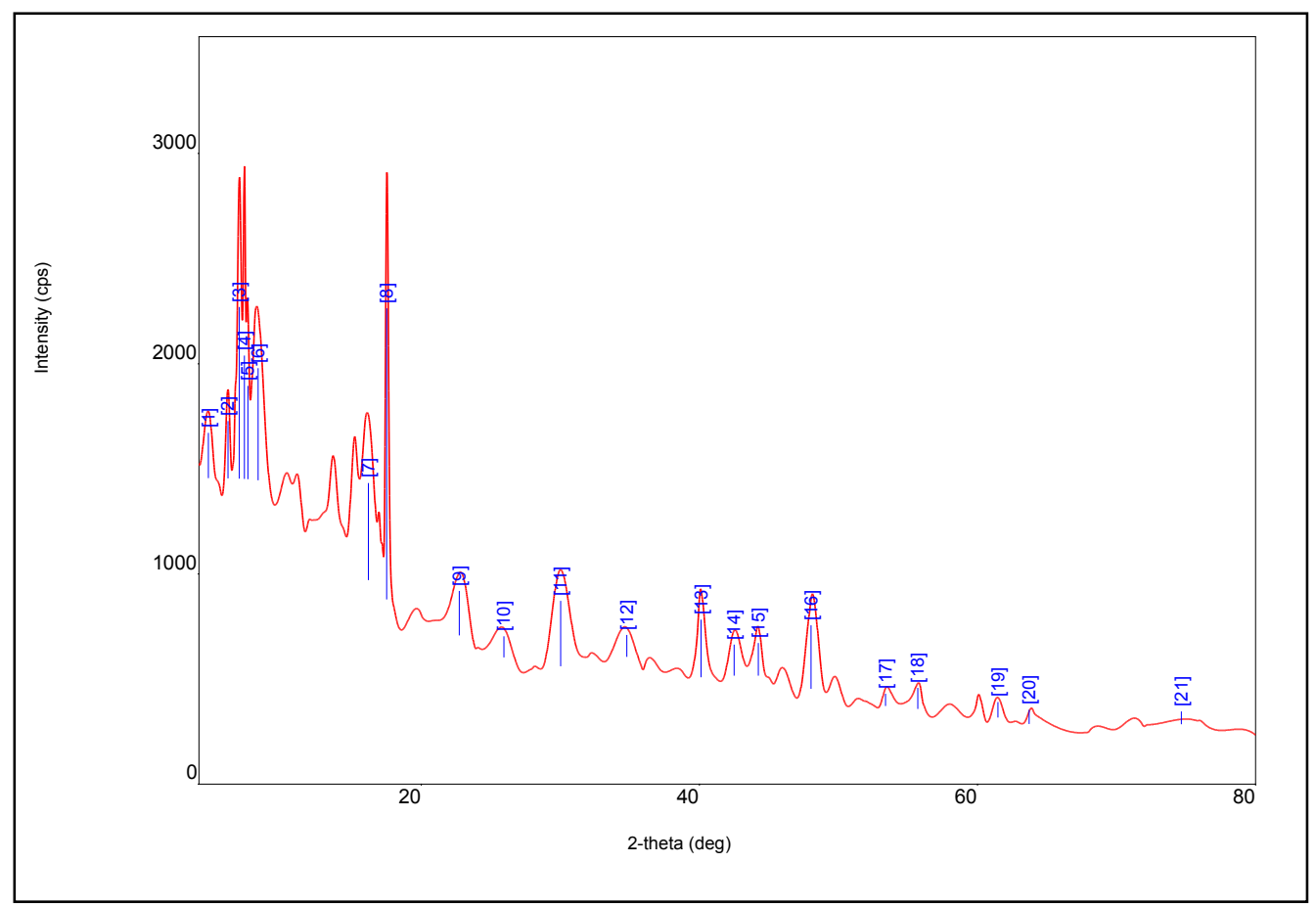

Fig. 2a. XRD pattern of synthesized Y zeolite. 


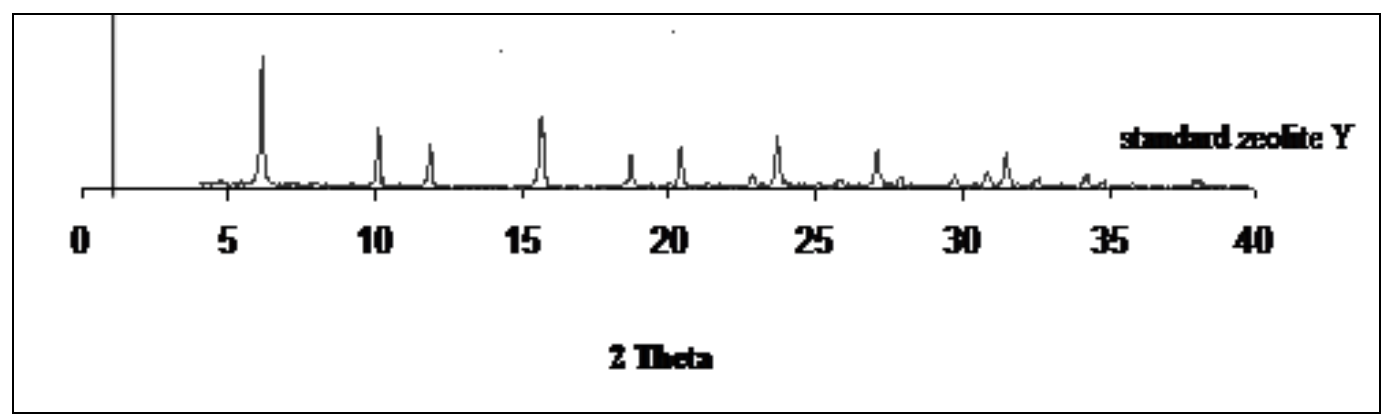

Fig. 2b. XRD pattern of commercial zeolite Y.

The product was characterized by Fourier transform infra-red (FT-IR) spectroscopy. The IR of zeolite after treatment (Fig. 3) shows strong IR absorption in the spectra region bellow $1200 \mathrm{~cm}^{-1}$ vibrations frequencies of the zeolite lattice which results from stretching and bending modes of the T-O units which is observed in the range $400-1100 \mathrm{~cm}^{-1}$ this indicates that $\mathrm{SiO}_{2}$ or $\mathrm{Al}_{2} \mathrm{O}_{3}$ are linked. The band at the 1018 and 773 referred to antisymmetrical and symmetrical stretching of Si-O-Si respectively, and the band centered at $3411 \mathrm{~cm}^{-1}$ due to the water molecules in the zeolite [20]. The band at $2356 \mathrm{~cm}^{-1}$ attributed to the organic compounds (mercabtanes) which adsorbed by zeolite. The FTIR spectra of synthesized zeolite $\mathrm{Y}$ is agrees with the typical FTIR absorption peaks of zeolite Y reported earlier [21].

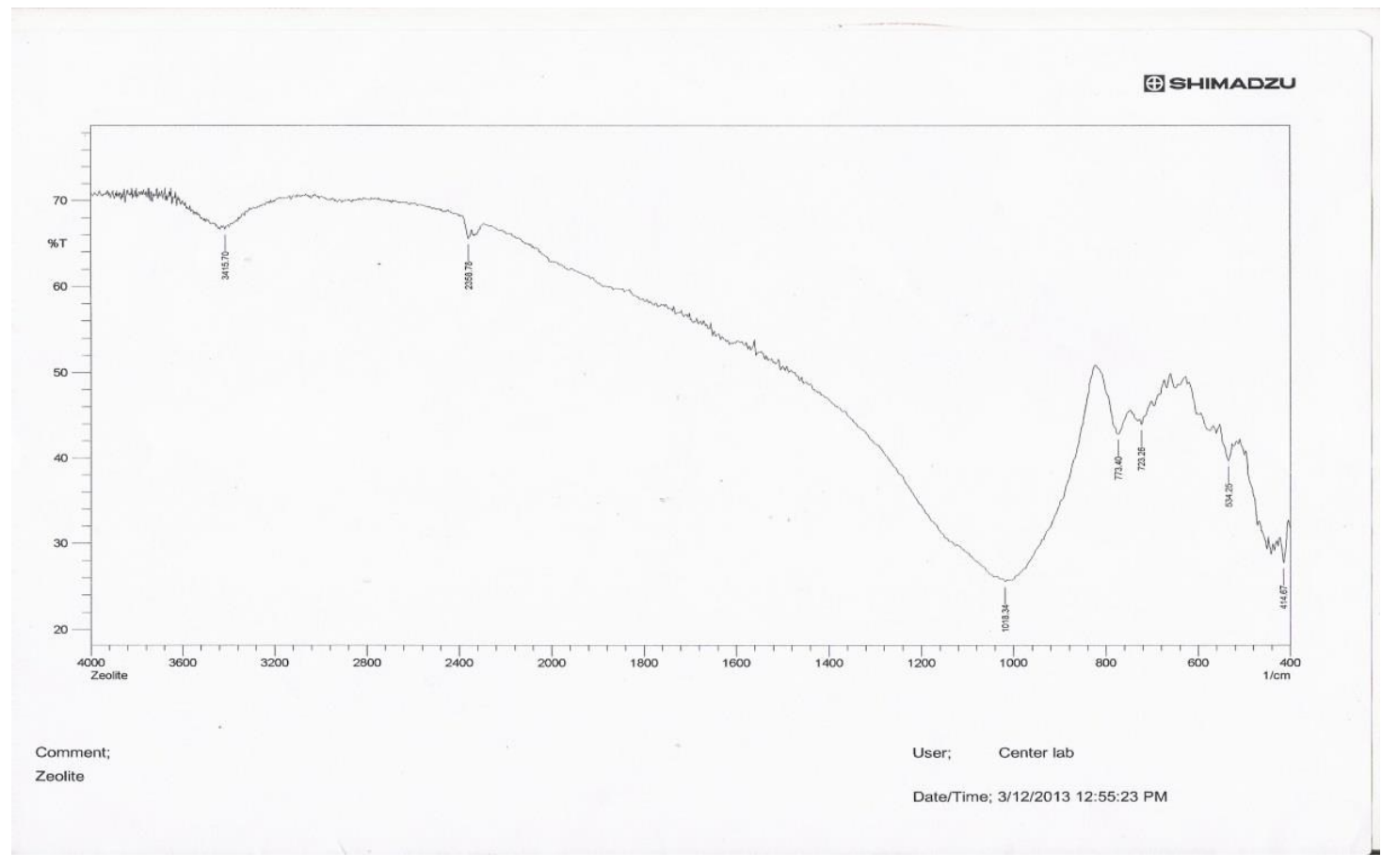

Fig. 3. FT-IR of zeolite after treatment.

The thermal gravimetric analysis (TGA) thermo grams of sample of zeolite before and after treatment are shown in figures (4a) and (4b) the zeolite before treatment underwent 
two weigh losses, the endothermic loss between $50{ }^{\circ} \mathrm{C}$ and $100^{\circ} \mathrm{C}$ is assigned to water adsorption, while for zeolite sample the water molecule found in its structure can be lost in the range between $130^{\circ} \mathrm{C}$ and $250^{\circ} \mathrm{C}$. These losses are the same for the two samples of zeolite (before and after treatment) but the difference between them is the loss of the organic compounds which are adsorbed by zeolite and it is shown in figure (3-2) in the range between $90^{\circ} \mathrm{C}$ and $200^{\circ} \mathrm{C}$. Zeolite has high thermal stability and it is stable until $500^{\circ} \mathrm{C}$, this is the desired property for any heterogeneous catalyst, and it can be separated and recovered easily after treatment of gasoline. In the case of the type II zeolite, the increment of the octane number seems to be due to the high aromatics content [22].

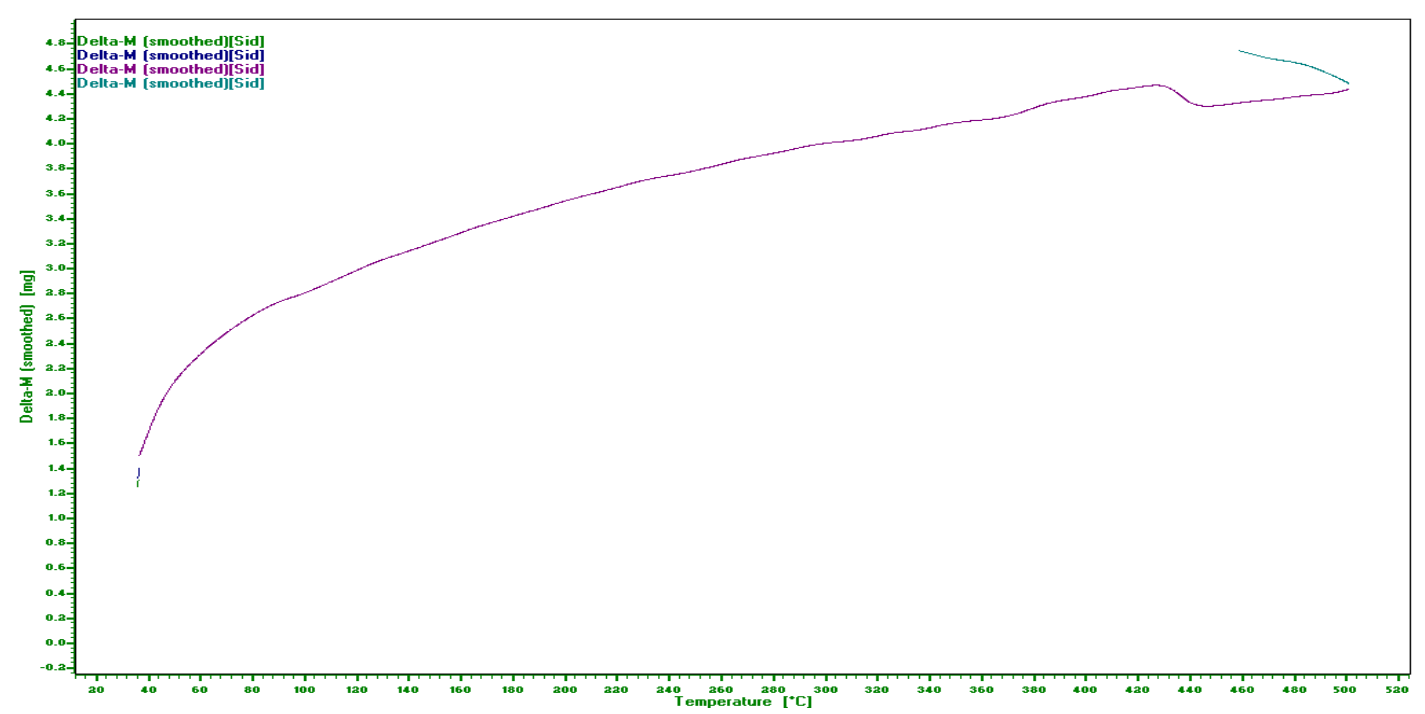

Fig. 4a. TGA diagram of zeolite before treatment.

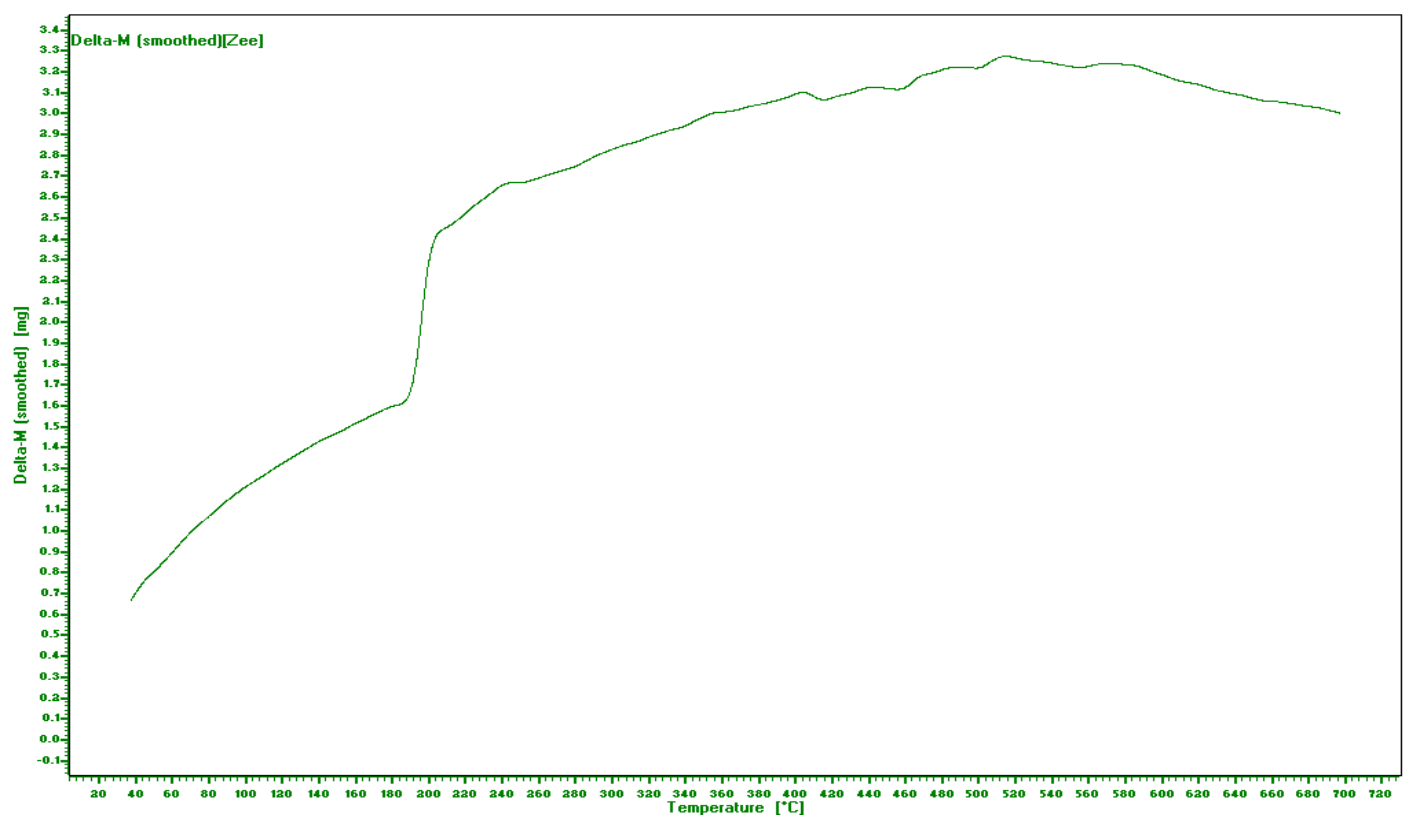

Fig. 4b. TGA diagram of zeolite after treatment. 


\subsection{Octane number, density and corrosion rate}

Table 2. Octane number, density and corrosion rate of gasoline before and after treatment with zeolite.

\begin{tabular}{|c|c|c|c|}
\hline Sample & $\begin{array}{c}\text { Research Octane } \\
\text { Number }\end{array}$ & $\begin{array}{c}\text { Density } \\
\left(\mathrm{g} . \mathrm{cm}^{-3}\right)\end{array}$ & $\begin{array}{c}\text { Copper strip } \\
\text { corrosion rate }\end{array}$ \\
\hline $\begin{array}{c}\text { Gasoline without } \\
\text { treatment }\end{array}$ & 91.7 & 0.7320 & $\left(3 \mathrm{~h} / 50^{\circ} \mathrm{C}\right) 1 \mathrm{a}$ \\
\hline Gasoline after treatment & 92.4 & 0.7285 & $\left(3 \mathrm{~h} / 50^{\circ} \mathrm{C}\right) 1 \mathrm{a}$ \\
\hline
\end{tabular}

The use of zeolite in refinery is very important to solve many problems of fuel, and it had many uses in refinery processes to produce friendly products. As the result of treatment the octane number of gasoline increased from 91.7 to 92.4 by zeolite. The empirical rules of octane number dependence on the structure of alkanes can be amended to become as follows: octane number decreases with the increasing of number of $\mathrm{CH} 2$ groups and arises with the increasing of the number of $\mathrm{CH} 3$ groups; the number of adjacent $\mathrm{CH} 2$ groups has the highest but sigmoid influence; octane number decreases with the separation between branches; - ON increases with the more central position of branches; - ON increases with the bulkiness of the branched structure. The zeolite destroys the alkane side chain by absorbing the $\mathrm{CH}_{2}$ which yields short side chain. This reason leads to enhancement of the octane number by zeolite which can be separated after treatment. This method is simple and economic.

The treatment process of gasoline by zeolite involves taking heavy oil such as kerosene or diesel and heating it to a high temperature in the presence of a catalyst. The large molecule breaks down into several smaller ones, some saturated, some unsaturated. The unsaturated products are used as feedstock for the polymer industry while the saturated products are usually high-octane branched chain alkanes suitable for making gasoline. In this process the density of gasoline was decreased after treatment from $\left(0.7320\right.$ to $\left.0.7285 \mathrm{~g} / \mathrm{cm}^{3}\right)$ this result lead to say when the octane number increase the density was decreased.

Crude petroleum contains sulfur compounds, most of which are removed during refining. However, of the sulfur compounds remaining in the petroleum product, some can have a corroding action on various metals and this corrosivity is not necessarily related directly to the total sulfur content. The effect can vary according to the chemical types of sulfur compounds present. The copper strip corrosion test is designed to assess the relative degree of corrosivity of a petroleum product. There was no deference between the blank and sample according to the corrosive effect of the copper strip. According to this result the copper strip corrosion of the sample was found in the normal range.

\section{CONCLUSION}

Zeolite are stable, non-toxic and preventing contamination of valuable feed stock's. zeolite is used as heterogeneous catalyst due to stability to cavity, its thermal at high temperature and secretive even at unfavorable reactant ratio and the reaction is ecofriendly. the synthetic zeolite is high activity more than natural zeolite because it is have high purity. Use of zeolites as a catalyst in the manufacture of some fine chemicals should 
expand. New zeolite catalyst should be developed with improve application selectivity and new functionalities, perhaps for strong base and oxidation catalysis. New ion exchange of new microporous oxide also may be expected. Experience has taught that availability of new material normally precedes by many years the discovery of all of their useful properties and the conception and development of new uses.

\section{References}

[1] Abel Derks, and .Co - SUDAN'S OIL INDUSTRY Facts and Analysis- April 2008$\mathrm{p}(1-2)$.

[2] Nahla Adam-Removal of paraffin wax from Sudanese Petroleum Products-MSc in chemistry Alneelain University- 2011- P(6-7).

[3] Motaz Elshaikh - enhance octane number by lithium zeolite- Elneelain university2013- p(4-35).

[4] Anton Perdih, Franc Perdih - Chemical Interpretation of Octane Number Department of Chemistry and Chemical Technology, University of Ljubljana, Aškerčeva 5, SI-1000 Ljubljana, Slovenia - Received 12-09-2005 - p (306 - 307).

[5] Miss Sudaporn Tangkawanit-Synthesis of Zeolites from Perlite and study of their ion exchange properties" A Thesis Submitted in Partial Fulfillment of the Requirements for the Degree of Doctor of Philosophy in Chemistry Suranaree University of Technology Academic Year 2004 - p (1 - 59).

[6] Hemmler CL, Tajb D G - in Handbook of petroleum Refining Processes - Myers R A ,Editor - New York; MC Grow - Hill 1997 - p(355). (7) R.G. 7. Bell - What are Zeolites - united kingdom- may 2010.

[7] JOHN D. SHERMAN, Synthetic zeolites and other microporous oxide molecular sieves, Proc. Natl. Acad. Sci. USA Vol. 96, pp. 3471-3478, March 1999]

[8] B. deKroes, C.J. Groenenboom and P. O'Connor, in: New Zeolites in FCC, Ketjen Catalyst Symposium, Scheveningen, Netherlands, (1986).

[9] Thomas F. Degnan, Jr. (2000). Applications of zeolites in petroleum refining, Topics in Catalysis 13, pp. 349-356.

[10] N.Y. Chen, W.E. Garwood and F.G. Dwyer, Shape Selective Catalysisin Industrial Applications (Dekker, New York, 1996).

[11] N.Y. Chen and T.F. Degnan, Chem. Eng. Prog. 84 (1988) 32.

[12] JOHN D. SHERMAN, Synthetic zeolites and other microporous oxide molecular sieves, Proc. Natl. Acad. Sci. USA Vol. 96, pp. 3471-3478, March 1999]

[13] Pramatha Payra and Prabir K. Dutta - Zeolites: A Primer - The Ohio State University, Columbus, Ohio, U.S.A - p (1-5).

[14] Scherzer J - Gruia A G - Hydrocracking science and technology - New York Dekker 1996.

[15] HUDE,Pavol (2011). FCC catalysis - Key Element in Refinery Technology, 45th Int. Petroleum Conf., 13th June 2011, Bratislava, Slovak Republic. 
[16] Cracking catalysts with octane enhancement US patent 4898846 A.

[17] D.W.Breck.(1974).Zeolite Molecular Sieves, John Wiley and Sons, Inc., New York.10:122.

[18] G.M Arifuzzaman khan, S.M.Y Arafat, M.N Reza, S.M Abdur Razzague and Md. Shamsul Alam.(2010).Linde Type - Synthesis and effect of crystallization on its surface acidity. Indian Journal of chemical Technology .17:303-308.

[19] M. M. Rahmana1 , N. Hasnidab , and W. B. Wan Nikb (2009). Preparation of Zeolite Y Using Local Raw Material Rice Husk as a Silica Source, J. Sci. Res. 1 (2), 285-291.

[20] Albert, B.R., Cheetham, A.K., Stuart, J.A., and Adams, C.J. (1998). Investigation on P zeolites:Synthesis, characterization and structure of highly crystalline low-silica NaP. Microporous and Mesoporous Materials., 21:133-142.

[21] Holmberg, B.A. H. Wang, J.M. Norbeck, and Y. Yan, Controlling size and yield of zeolite Y nanocrystals using TMABr. Microporous and Mesoporous Materials, 2003. 59: p. 13-28.

[22] T. Tsutsui, Y. Ueda, K. Ijichi, K. Mizuta and Y. Uemura, 2010. Evaluation of Catalytic Cracking Reactivity of Zeolites using 1-Dodecene as a Model Feedstock-Classification of Zeolites Based on Hydrogen Transfer Reactivity. Journal of Applied Sciences, 10: 3215-3221. 